\title{
O FENÔMENO GRANJEIRO E OS CONDOMÍNIOS EM ALDEIA: UMA NOVA PERIFERIA EM CONFORMAÇÃO
}

\author{
The phenomenon granjeiro and condos in Aldeia: a new periphery in \\ conformation
}

\author{
Ailson Barbosa da Silva \\ Professor Assistente da Universidade Estadual do Maranhão \\ Ailson.barbosa.silva@gmail.com
}

Artigo recebido em 25/03/2017 e aceito para publicação em 04/09/2017

DOI: $10.12957 /$ tamoios.2017.28020

\section{RESUMO}

Em função do processo de saturação das cidades e do aprofundamento da problemática urbana, as novas periferias têm se tornado uma alternativa para as famílias de renda média que passam a ocupar as áreas mais distantes dos centros urbanos tradicionais produzindo áreas marcadas por um novo tipo de urbanização: dispersa e fragmentada. A fim de analisar esse quadro teórico tomamos como objeto de investigação a região de Aldeia (Camaragibe-PE). Esta nova periferia, localizada na parte oeste da Região Metropolitana do Recife, tem sido palco de importantes mudanças na forma de uso do solo e de conteúdo social. O processo por qual passa a região dá origem a uma espacialidade marcada pela ação de interesses do mercado imobiliário alterando a clássica lógica da periferia marcada pela pobreza. Para realização deste trabalho foi procedido uma revisão da literatura e uma série de entrevistas com moradores da região. $\mathrm{O}$ trabalho tem por objetivo refletir a respeito do processo de formação da nova periferia de Aldeia.

Palavras-chave: Nova periferia, Condomínios horizontais, Urbanização, Camaragibe.

\begin{abstract}
Role of process saturation of cities and deepening urban problematic as new peripheries has become a alternative as income families average passing one occupy areas as far more of traditional urban. To this end, we as object research the case Aldeia (Camaragibe -PE). This new outskirt, located in the western part of the Region of Recife Metropolitana has been stage important Changes in the way of using the Solo and social content. The process in qua passes the Source Region of spatiality a marked for real estate market interests action changing the classical logic periphery marked by poverty. For this work was carried a literature review and a series of interviews with residents of the region. The study aims to reflect the training process regarding the new periphery Aldeia.
\end{abstract}

Keywords: New outskirts, Horizontal Condominiums, Urbanization , Camaragibe . 


\section{INTRODUÇÃO}

O debate a respeito das novas periferias está na pauta atual da geografia urbana e das ciências humanas como um todo. Variados trabalhos têm se proposto a refletir e compreender os processos que originam essas espacialidades que rompem com a velha lógica centro versus periferia e avançam, cada vez mais, para formação de novas centralidades.

As novas periferias se destacam pelos negócios e contingente que tendem a ocupá-las. Essas áreas se reproduzem como alternativas, não centrais, para negócios e famílias de alto padrão de renda. Em muitos casos, os produtos imobiliários ofertados para tratar da oferta habitacional - se destacam pela possibilidade de consumo de exclusividades espaciais, condição de segurança e qualidade de vida, além da representação de status relacionado à moradia. Essa periferia não corresponde às clássicas periferias brasileiras, mas a um novo tipo de periferia marcado pelo jogo de interesses dos agentes produtores da cidade, pela presença de negócios exclusivos, pela presença de um conteúdo social distinto, pela compleição do Estado e pelas boas qualidades ambientais.

O presente trabalho tem por objetivo refletir a respeito do processo de constituição de uma nova periferia que vem se transformando em função do jogo de interesses urbanos. Essa nova periferia é marcada pelo avanço da urbanização, pela transformação na forma de uso do solo, pela redução das atividades rurais e pela penetração de interesses urbanos e imobiliários com rebatimentos na economia local, na estrutura social e na paisagem. Desta forma, a localidade de Aldeia (Camaragibe-PE) nos oferece um excelente exemplar de uma porção espacial que se constitui como uma nova periferia urbana e que se torna palco de disputas que envolvem interesses urbanos, disputas ambientais e uma larga trajetória de transformações espaciais.

\section{NOVAS PERIFERIAS}

O termo "novas periferias" busca dar conta de espacialidades periféricas localizadas em porções espaciais mais distantes dos tradicionais centros urbanos. Ainda que as tratemos como periferias, estas espacialidades se distinguem das tradicionais periferias clássicas pelo conteúdo social que o ocupa e pelos interesses que envolvem a sua produção.

Enquanto que as periferias clássicas são ocupadas por famílias mais pobres e sofrem com a ausência do Estado, as novas periferias se destacam pela presença e interesse de famílias de média e alta renda, somado à presença do Estado que organiza e regulariza a sua ocupação.

Por outro lado, as novas periferias são produzidas segundo um conjunto de interesses do mercado que, em certo momento, decide estabelecer vetores de expansão do tecido urbano em determinadas direções. Para estas áreas são direcionados investimentos privados e estatais, de forma a valorizá-la e torná-la atrativa, para quem pode pagar.

É importante destacar que em muitos casos o poder do marketing é mobilizado para promover uma valorização espacial dessas localidades.

Para diferenciá-las das tradicionais periferias problemáticas, amplamente debatida pela literatura brasileira, as novas periferias ganham, pois, adjetivos como nova, status $e$ amenidades. Contudo, este tem sido um termo mais utilizado dentre investigadores urbanos, já que pelo mercado tem preferido dar outras nomenclaturas a esses espaços. $\mathrm{O}$ termo periferia continua carregado de um sentido negativo, assim o mercado tem 
preferido falar de bairros planejados, condomínios horizontais ou evidenciar as qualidades ambientais e de exclusividade de certas porções.

Se no Brasil o fenômeno das novas periferias é recente, em nível internacional ele se desenrola desde o início do século XX. A este respeito, Egler (2001, p.15) assinala que "o processo de expansão dos espaços periféricos começou cedo nos países anglosaxãos, onde a classe média já estava migrando rumo aos primeiros subúrbios no início do século XX". Segundo o autor, o objetivo desse movimento rumo à periferia era procurar melhor qualidade de vida fora das grandes cidades que apresentariam disfunções afetando o cotidiano da população, tais como: congestão viária, criminalidade, poluição, preço elevado dos aluguéis etc.

Por sua vez, George (1983) destaca haver em Roma em meados do século XX, um movimento de operações imobiliárias que visavam incorporar propriedades rurais ao espaço de expansão do tecido urbano. O autor verifica neste contexto o início da intensificação de deslocamento de famílias de mais alta renda do centro para a periferia. Também discutindo o caso europeu, Asensio (2005) destaca que o movimento das famílias para aos subúrbios vem acontecendo, principalmente, entre famílias com fillhos menores, jovens casais e entre famílias de mais alta renda que buscam manter-se em contato com a natureza ou ter acesso a moradia própria. Em muitos casos, moradias de segunda residência acabam por se converter em moradia principal das famílias que encontram nas áreas periféricas a tranquilidade e a qualidade de vida que a cidade já não oferece.

Sánchez (2009, p.105) considera que "Na América Latina, o processo de periurbanização está essencialmente marcado pela heterogeneidade dos agentes sociais e dos processos espaciais, com uma alta mobilidade e incidência no jogo de forças que constroem o território". Nesse sentido, o autor define um traço comum no processo de periurbanização latino-americano: a periurbanização residencial. Enquanto que nos países industrializados a periurbanização é decorrente do deslocamento de indústrias, moradias e negócios de serviços, na América Latina este processo é marcado, sobretudo, pela expansão residencial de famílias de média e alta renda.

No Brasil, as novas periferias - resultado da conjunção de diversos processos espaciais e de interesses econômicos - correspondem a espaços de fuga onde é possível encontrar qualidades ambientais que os núcleos urbanos já não oferecem. Contudo, é preciso considerar que além das escolhas dos indivíduos, a produção das novas periferias atendem aos interesses de grupos econômicos que lucram com o processo de reprodução do espaço urbano.

Cabe destacar que somente há pouco mais de meio século (a partir dos anos 1950) o Brasil vivencia um processo de aceleramento da urbanização e este fenômeno vem resultando na degradação da qualidade de vida nas cidades. Isso colocou em xeque a permanência de parte das famílias, sobretudo aquelas que poderiam escolher onde morar, nas áreas centrais das cidades. Como consequência o que se viu foi $o$ deslocamento das moradias para pontos mais distantes das áreas centrais provocando a criação das chamadas novas periferias urbanas.

Para Spósito (2004, p.11) o processo de produção de novas periferias no Brasil decorreu de um conjunto de três fatores principais:

i) influência dos princípios do urbanismo progressista, fortemente apoiado nas ideias de Le Corbusier, teve papel fundamental na ampliação territorial das cidades, durante o século XX. A leitura da Carta de Atenas possibilita a apreensão dos princípios que sustentavam essa proposta. A ideia de diminuição da densidade dos 
assentamentos urbanos, por meio da convivência, nas cidades, entre áreas construídas e áreas verdes foi um vetor da extensão urbana.

Os interesses fundiários e imobiliários são, sem dúvida, os motores principais da extensão da cidade. A lógica de produção do espaço urbano tem sido orientada pela implantação de novos loteamentos e pelo contínuo lançamento de novos produtos imobiliários de forma a se atingir novos consumidores e/ou se estimular novas demandas àqueles que já haviam consumido esses produtos imobiliários anteriormente.

iii) Por último, é preciso lembrar que a tendência à contínua expansão territorial urbana, verificada no século XX, constitui expressão das possibilidades técnicas que a invenção da geladeira e do transporte automotivo propiciaram. Se o trem e o bonde tiveram grande importância na origem do padrão de suburbanização que se originou na segunda metade do século XIX, a difusão do uso do automóvel foi fundamental para o aparecimento de novas formas de habitat urbano que geraram novas práticas socioespaciais, a partir da década de 1920 nos Estados Unidos, e logo depois da $2^{\text {a }}$ Guerra Mundial na Europa.

Desta forma, o processo que se estabelece no Brasil é resultado de um ideal que buscou contrapor a dispersão em relação à aglomeração e os novos produtos imobiliários aos estoques envelhecidos. Somado, pois, ao desenvolvimento de tecnologias, de transporte e comunicação, as novas periferias surgem como opção a condição problemáticas das áreas centrais das cidades.

Para Lago (2006) existe, hoje, uma forte tendência de mudança no padrão do espaço metropolitano brasileiro. Isto tem produzido uma nova configuração urbana rompendo-se, pois, com o velho modelo centro versus periferia. O processo de elaboração das novas periferias, para onde tenderam a se deslocar investimentos de capital e famílias de maior poder renda, acompanhou, pois, a emergência de novos ideais e paradigmas da sociedade contemporânea.

Foi quando a cidade passou a enfrentar uma realidade problemática e de deseconomias que as periferias passaram a ser tomadas como espaço de prestígio (BHERING \& MONTE-MÓR, 2005). Em verdade, estes espaços passam a receber demandas e contingentes populacionais, servindo, pois, como espaço alternativo ou de fuga, como temos preferido chamar.

É interessante atentar para o fato de que muitas dessas novas periferias são espaços preteritamente rurais e que mais e mais ganham funções e conteúdos urbanos. Por um lado, estes espaços buscam manter seus aspectos de ruralidade como forma de agregar valor midiático e mercadológico para os novos negócios, por outro lado vão sendo produzidos e influenciados através de uma lógica urbano-industrial.

É importante compreender as novas periferias como espaço alternativo para camadas de médio e alto poder de renda. Tais espaços se tornam opção aos espaços problemáticos das cidades, contudo buscam reproduzir na periferia aquilo que as cidades oferecem de melhor. Há, pois, ao mesmo tempo, um processo de negação da cidade e de reprodução da mesma.

Nesse bojo, criam-se vetores residenciais de alto padrão onde se reproduzem simulacros da cidade na forma de condomínios fechados (CALDEIRA, 2000), verdadeiras fortalezas nas quais grupos economicamente abastados manterão um distanciamento dos problemas da cidade real. 


\section{A LOCALIDADE DE ALDEIA}

Para o desenvolvimento do presente trabalho selecionamos a localidade de Aldeia $^{1}$ (Camaragibe-PE), região que vivencia um processo de periurbanização recente e que nos oferece a possibilidade de reflexão sobre uma região marcada pela de mescla usos rural e urbano, um mix de conteúdo social e transformações de ordem econômica, social e espacial.

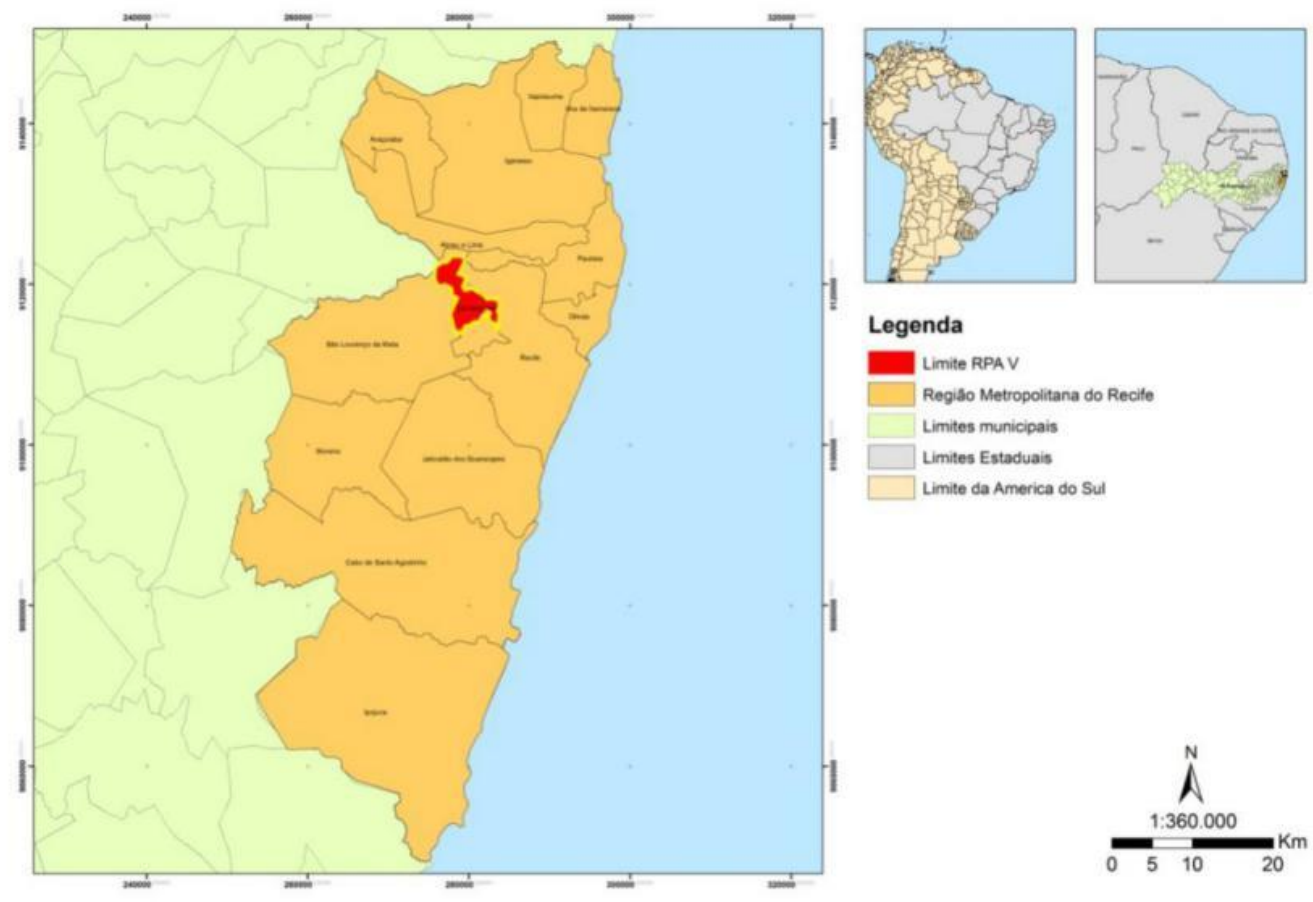

Figura 1: Localização de Aldeia em relação ao conjunto da Região Metropolitana do Recife

Aldeia está situada na parte Oeste da RMR (Região Metropolitana do Recife) e na parte norte do município de Camaragibe. Possui uma população de 17.166 habitantes (IBGE, 2010) que está distribuída sobre uma área de pouco mais de $30 \mathrm{~km}^{2}$, apresentando uma baixa densidade populacional, a menor dentre as RPAs do município. Atualmente, em Aldeia são encontrados variados empreendimentos imobiliários na forma de condomínios horizontais que se mesclam com granjas, chácaras, terrenos baldios e atividades agrícolas, conformando um grande espaço híbrido rural-urbano.

Aldeia foi se constituindo como uma nova periferia de status e amenidades sendo, pois, uma opção de fuga e prestígio para parte das famílias de renda média recifenses. Foi frente à condição problemática do núcleo metropolitano do Recife que ao longo das últimas décadas variadas famílias estabeleceram ali suas moradias de lazer ou até mesmo moradia principal. Se no passado recente, Aldeia era uma área tradicional de segunda residência, hoje, em função dos novos negócios imobiliários, do desenvolvimento técnico e das melhorias estruturais, a região se caracteriza como área predominante de primeira residência. E é em função desses moradores fixos na localidade que variadas mudanças vem ocorrendo na estrutura social, econômica e na paisagem. 


\section{DO GRANJISMO AOS CONDOMÍNIOS: UMA NOVA PERIFERIA}

O passado de Aldeia, e mesmo a sua formação, está diretamente relacionado ao fim das atividades dos engenhos Aldeia e Camaragibe e à criação das primeiras granjas, chácaras e clubes de lazer na região. Ainda assim, as granjas representaram um elemento dinamizador da economia em função do processo de produção de alimentos e de abastecimento, ainda que pequeno, do núcleo urbano recifense. Neste sentido, falamos de fenômeno granjeiro ou granjismo para nos referir a um processo de instalação e funcionamento das granjas produtivas em Aldeia com grande importância para a história de nosso objeto.

O granjismo corresponde a um neologismo elaborado para dar conta de um processo local de formação de uma tipologia da periferia marcada pela implantação de unidades produtivas e de segunda residência no entorno da RMR. Este processo remonta a primeira metade do século XX com forte presença nos municípios limítrofes à capital recifense. Segundo Miranda (2008) o termo granja está associado à idéia de pequenas unidades rurais produtivas de uso avícola e/ou hortifruticultora com dimensões que variam de 1,0 ha a 20,0 ha, fruto do loteamento rural.

Além da atividade agrícola, as granjas estão associadas atualmente ao uso de lazer e de segunda residência. "Muitas vezes localizadas dentro do perímetro urbano, as granjas deixam de ser um lote rural, porém conservam a toponímia. Denominam-se como granja o que comumente se designaria como chácaras, por seu uso e proximidade do centro urbano" (Idem, p.267).

O fenômeno granjeiro aldeense se desenvolveu em um período em que o crescimento do núcleo urbano recifense demandava um centro de produção alimentar próximo. Nos anos 1950, foi criado, através do decreto ${ }^{\circ} 40.554$ de 14 de dezembro de 1956, o Grupo de Trabalho para o Desenvolvimento do Nordeste - GTDN. Este grupo foi encarregado de apresentar um novo projeto para reorientar o desenvolvimento sócioeconômico da Região. Como proposta deste grupo foi elaborado um relatório denominado "Uma Política de Desenvolvimento Econômico do Nordeste", que apresentava ideias relacionadas à questão da terra.

Quanto à pequena produção rural a proposta mais interessante foi a de reorientar a produção agrícola na faixa úmida da Região Nordeste, visando a produção de gêneros alimentícios para abastecer o mercado interno. Nesta direção, a estrutura fundiária da Zona da Mata deveria ser modificada para viabilizar a expansão da pequena produção, no sentido de formar um "cinturão verde" em torno das cidades que se industrializavam (SUDENE, 1978, p.89). Desta forma, a formação de um cinturão verde no entorno do Recife, capaz de atender às necessidades alimentares da população local, impulsionou o fenômeno granjeiro na região e funcionou como um primeiro momento da formação daquela que se transformou a nova periferia recifense.

Esta fase se refere a meados do século XX, quando o processo de loteamento de terras na região é reforçado, sobretudo, pela abertura da PE-27. Logo, muitas famílias adquiriram lotes de terras em Aldeia tanto para criação de unidades produtivas quanto para espaços de lazer.

Para algumas famílias possuir um lote de terras em Aldeia correspondia a uma condição de status social e um investimento (COSTA, 1960), já para outras adquirir terras para pequena produção rural se constituía numa alternativa de sobrevivência ou de reprodução da tradição agrícola familiar.

As granjas que se estabelecem em municípios mais distantes do Recife concorreram, sobretudo, com a atividade de monocultura canavieira. Para Costa (1960) se o granjismo não veio solucionar a problemática elaborada pela monocultura ao 
menos possibilitou conservar o "status quo". Diversos proprietários de engenhos, frente ao esgotamento de suas atividades, viram-se obrigados a desfazer-se de suas terras. "Não podendo ou não querendo recuperá-lo [os proprietários de terras] preferiram lotear [os engenhos] ou auferir a renda resultante que é bastante considerável" (p.74).

Uma característica importante deste fenômeno diz respeito à sua localização que predominava na Zona da Mata pernambucana, sobretudo pós anos 1940. Para Costa (p.75) "Quanto à zona de incidência das granjas, podemos ver que se estende seguindo em linhas gerais as autoestradas ou formando manchas nas suas proximidades, com maior ou menor intensidade, dependendo de diversos aspectos especiais". É interessante perceber que o caso de Aldeia manteve uma relação direta com a abertura da PE-27.

Segundo Costa (1960) não sendo um fenômeno rural, pois sua estrutura é eminentemente da cidade, as granjas se alimentaram de uma lógica tradicionalmente urbana. Neste sentido, a autora destaca haver na região de Aldeia, já no fim dos anos 1950, a presença de inúmeras granjas onde podia ser percebida a presença de casas de luxo que, para a autora, se voltavam a substituir o modelo de casas senhoriais dos engenhos açucareiros e avançavam mais no sentido de reproduzir o casario americano e europeu. Se por um lado as casas apresentavam grande ostentação em termos de estrutura (muitas das quais com piscinas), por outro reproduziam os costumes da cidade. Logo, a garagem era item obrigatório nas granjas, sobretudo porque o automóvel particular representava a única alternativa para as visitas nos finais de semana. Neste sentido, afirma que a Estrada estava repleta de granjas "cujos tamanhos são tão variáveis, mas é talvez onde se encontram as mais ricas e luxuosas vivendas de campo" (p.77). As casas de luxo que se refere a autora continuam existindo, mas hoje já não representa um imobiliário tão moderno e sofisticado quanto aqueles que tem sido produzido em outras partes RMR.

É interessante atentar que ao longo dos últimos anos um novo processo é verificado em Aldeia. O granjismo perde importância sendo substituído por atividades de lazer ou mesmo por negócios imobiliários - a forma de condomínios horizontais. A redução do granjismo se relaciona a um conjunto de fatores identificados por Silva (2015), dentre eles:

- Os limites técnicos e a concorrência com grandes empresas produtoras;

- A falta de políticas públicas e de incentivo para pequenos produtores, sobretudo para os granjeiros de Aldeia, situados em área legalmente urbana; e

- A dificuldade de acesso a insumos (vindos de outros estados) e os elevados encargos trabalhistas.

O conjunto desses fatores, somados à pressão imobiliária sobre muitos granjeiros, tem diminuído fortemente o granjismo na região que, hoje, se reduz a um grupo de meia dúzia de granjas produtivas.

Atualmente variadas granjas e chácaras funcionam como moradias principais de diversas famílias que, fugindo da problemática recifense, encontraram naquela região um espaço de paz, segurança, tranqüilidade e qualidade de vida. Assim, é comum ouvir relatos de moradores locais que falam com entusiasmo sobre a possibilidade de viver em uma casa espaçosa, com quintal e em contato direto com a natureza. $\mathrm{O}$ discurso ambiental foi fortemente utilizado pelo mercado imobiliário que transformou seus novos produtos - condomínios horizontais - em paraísos onde era possível viver em contato com a natureza e consumir os benefícios de uma vida rural próximo do núcleo metropolitano recifense. 


\section{OS CONDOMÍNIOS HORIZONTAIS EM ALDEIA}

Uma ampla produção acadêmica tem se proposto a refletir sobre os condomínios horizontais no Brasil. Esta forma de morar é inaugurada no país nos anos 1970. Os condomínios horizontais não são uma invenção nacional, mas um mimetismo dos subúrbios americanos (CALDEIRA, 2000). Se no Brasil os condomínios só passam a ser produzida na década de 1970, já se tinha exemplares em outras partes do mundo em décadas anteriores. A este respeito ver Carlos (1994) e Caldeira (2000) que estudaram os primórdios e a evolução dos condomínios fechados no país.

A formação de espaços residenciais fechados remonta o século XIX com a privatização das ruas de San Luis (Missouri) nos Estados Unidos e a criação de subúrbios fechados em Nova York (BLAKELY E SNYDER, 1997). Na América Latina Svampa (2001) destaca a existência dos primeiros barrios cerrados na Venezuela nos anos 1920 e dos espaços residenciais fechados em Buenos Aires, nos anos 1930.

Não Brasil foi a cidade de São Paulo que inaugurou, a partir dos anos 1990, esta tendência de produção habitacional (marcada por isolamento, segurança e exclusividade) para famílias de maior poder aquisitivo. O modelo elaborado em São Paulo ganha exemplares em diversas partes do Brasil, ainda que apresentem diferenças em termos estruturais (SOUZA, 2000). Contudo, além de pioneira nesta tipologia habitacional, São Paulo também inaugura uma nova forma de ocupação das periferias elaborando uma tendência de produção imobiliária para as elites em regiões distantes da área central. Assim, os condomínios reforçaram o processo de suburbanização da metrópole paulistana e de outras cidades brasileiras.
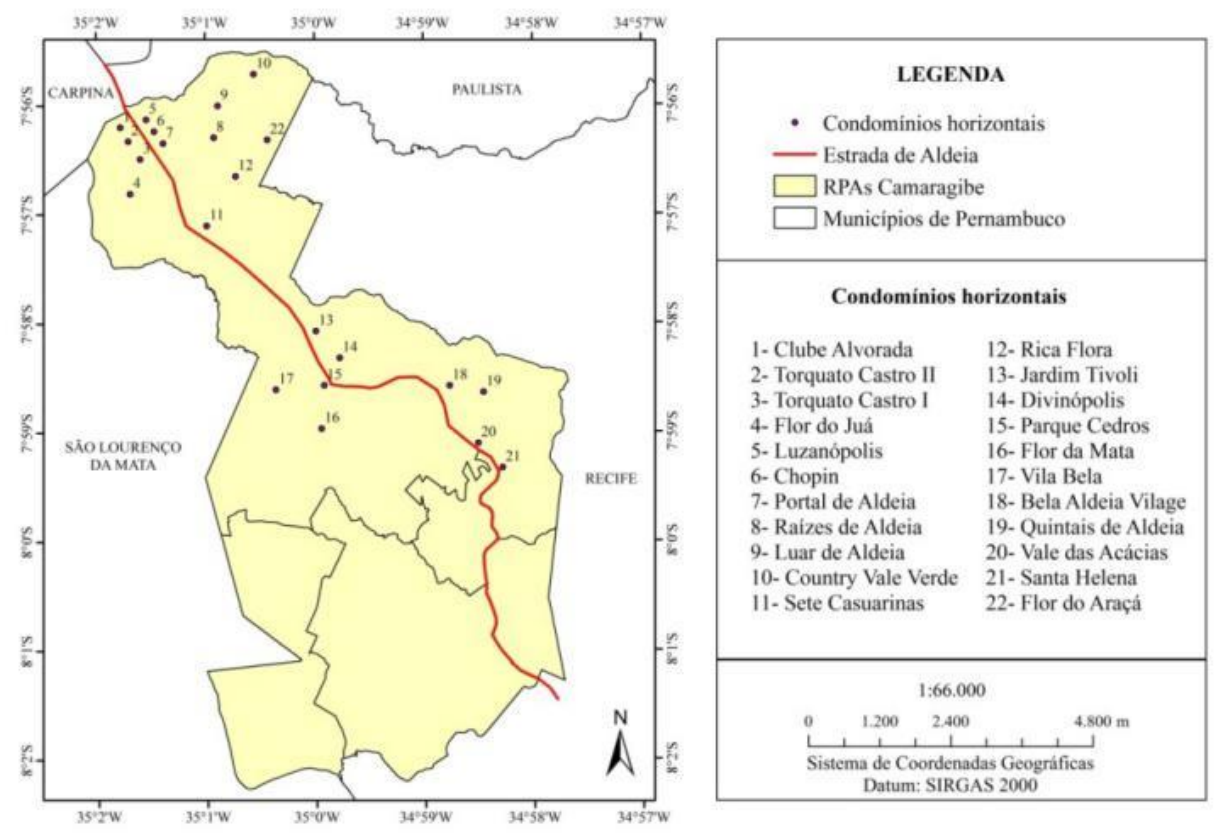

Figura 2: Distribuição dos condomínios horizontais no município de Camaragibe

Diferente do que ocorreu nos subúrbios de São Paulo, no Recife os condomínios horizontais não se tornaram destino de famílias mais abastadas. A maior parte dessas famílias continuaram ocupando a parte norte do Recife e mesmo os empreendimentos localizados ao longo do litoral. Para Aldeia, por sua vez, rumaram parte das famílias de renda média, e até algumas de renda média-alta, que enxergavam na região uma 
possibilidade de fuga da problemática metropolitano, tal como de um reencontro com a natureza.

Os condomínios inauguram a entrada de uma lógica imobiliária lançada para região de Aldeia lançada pelos tentáculos da urbanização metropolitana. Se antes, com as granjas, o processo de compra e venda das unidades imobiliárias se dava, quase que exclusivamente, de forma direta entre comprador e vendedor, com os condomínios horizontais aldeenses a lógica imobiliária adentra a localidade contando, pois, com a operação de agentes imobiliários especializados na venda de imóveis.

Este fato é reforçado pelo número de empresas imobiliárias presentes na Estrada de Aldeia, sobretudo, e que se propõem a comercializar os condomínios localizados na região (SILVA, 2011). Assim, é interessante perceber que os condomínios atraem uma nova lógica de comercialização para Aldeia superando as formas tradicionais de comércio imobiliário.

O fenômeno dos condomínios horizontais em Aldeia remonta os anos 1990, quando o granjismo começava a perder importância no contexto metropolitano e o núcleo recifense já deva sinais de saturação. A violência, os congestionamentos, a poluição sonora e ambiental e a degradação da vida urbana tornam-se fatores de repulsa para muitas famílias. Assim, sobretudo aquelas famílias com mais poder de renda, o processo de descentralização (CORREA, 1989) ou escapismo (SOUZA, 2000) surge como alternativa, sobretudo, em meio à emergência de um paradigma residencial aliado à natureza.

É mediante esta realidade que promotores imobiliários passam a mirar nas bordas da RMR promovendo discursos de alternativa aos problemas urbanos e oferecendo um novo tipo de produto imobiliário. Assim, mediante o quadro problemático da RMR, Aldeia surge como uma alternativa de fuga, sobretudo quando o núcleo recifense se converte em deseconomia, relacionadas à violência, poluição e segurança precária.

Os condomínios se transformaram, assim, em espaço onde era possível reencontrar "o paraíso". Em Aldeia, estes empreendimentos representaram a possibilidade de reprodução da cidade, ou melhor, a cidade e suas qualidades. Rumar para Aldeia significou encontrar os benefícios do espaço urbano no meio rural. É interessante chamar atenção para o fato de empreendedores criarem discurso rural para Aldeia, em verdade, buscando explorar as características ambientais ali existentes.

A partir dos anos 1990, variados empreendimentos foram lançados naquela região e se estes surgiam sob o signo da solução à problemática urbana recifense, hoje, eles se transformaram em parte da reprodução dos problemas. A fixação de moradores nos condomínios e granjas residenciais em Aldeia representou o aumento no uso do carro particular que tem provocado uma grande problemática de mobilidade. Sobretudo, em função de que a região apresenta uma única possibilidade de acesso, através da PE27, o que tem causado grandes transtornos para a população local.

Os empreendimentos ali instalados se prevalecem do acesso à Estrada, principal forma de acesso à região, tornando-se elemento de valorização. Além disso, outro elemento que agrega valor aos empreendimentos é a presença de amenidades naturais, destacadas nas propagandas de marketing, como elemento de destaque de muitos dos condomínios. Viver próximo à natureza, respirar ar puro, ter contato com fontes de água e rios e experimentar a proximidade com a fauna local são argumentos encontrados em muitas das peças publicitárias desses empreendimentos.

Ocupados por famílias de renda média e que apresentam uma demanda significativa de prestadores de serviços e negócios, os condomínios atraíram diferentes atividades e pessoas para a região aquela região. Assim, como já estudado em Silva 
(2011), a presença desse contingente de renda média habitando os condomínios locais além das granjas e chácaras - atraíram um significativo contingente de trabalhadores em busca de oportunidades de emprego na região. Logo, ex-agricultores encontraram oportunidades de trabalho como caseiros (nas granjas e chácaras) e, principalmente, como prestadores de serviços, nos condomínios horizontais. Em função disso, ocorreu um efeito imã com a criação de uma rede de solidariedade entre trabalhadores através da qual quem já estava empregado contribuía para a atração de outros. Como resultado desse processo migratório ocorreu a criação de uma periferia pobre em Aldeia, no bairro de Vera Cruz, que funciona como reserva de mão-de-obra para a população de classe média de Aldeia.

Além disso, um significativo número de negócios passa a fazer da paisagem local. Logo, farmácias, escritórios, armazéns de construção, supermercados, padarias, postos de gasolinas, cafés etc. tornam-se parte da paisagem de Aldeia, sobretudo ao longo da PE-27. Estes novos negócios passam a atender a demanda local, ainda que grande parte da demanda seja atendida no núcleo recifense, como demonstrado por Silva (2015).

O resultado do processo aqui descrito, em termos espaciais, foi a configuração de uma nova periferia de amenidades. Por um lado, se viu a redução do granjismo e das atividades rurais, por outro, se viu o avanço da urbanização metropolitana e uma mudança na lógica de uso do solo. Os condomínios horizontais de Aldeia reforçaram uma tendência de descentralização, periurbanização residencial e fragmentação do tecido metropolitano, ainda que permaneça no núcleo recifense uma forte tendência à verticalização.

A necessidade de grandes glebas de terras para promoção deste tipo de empreendimento e o consequente esgotamento do estoque de solo na RMR, vem provocando o crescimento da oferta de empreendimentos condominiais fora do tecido metropolitano e, agora, verifica-se com grande intensidade a conformação de uma região perimetropolitana que avança em direção à Zona da Mata pernambucana. Este movimento de saída vem sendo influenciado pela duplicação da BR-232 que atuou como eixo de dispersão da metrópole a Oeste à medida que favoreceu a implantação de novos negócios imobiliários - na forma de condomínios horizontais.

\section{NOTAS}

1 - O que aqui consideramos como Aldeia corresponde à RPA 5 do município de Camaragibe e compreende os bairros de Aldeia, Borralho, Oitenta e Vera Cruz.

\section{REFERÊNCIAS BIBLIOGRÁFICAS}

ASENSIO, Pedro José Ponce. Cambios sociales y espaciales en espacios perirubanos del País Valenciano. Un caso particular: El Puig de Santa María. Trabalho de fim de curso. 2001.

BHERING, Iracema A., MONTE MÓR, Roberto. Dinâmica do Crescimento das cidades brasileiras: pobres periferias ricas. In: Novas periferias metropolitanas. Belo Horizonte: Ed.C/arte, 2005, p. $291-312$.

BLAKELY, E. J. e SNIDER, M. Fortress America. Gated Commmunities in the United States. Cambridge/Washongton: Brooking Institution Press/Lincoln Intitution of Land Policy, 1997. 
CALDEIRA, Teresa Pires do Rio. Cidade de muros, segregação e cidadania em São Paulo/Teresa Pires do Rio Caldeira. São Paulo: Ed. 34; EDUSP, 2000.

CARLOS, Ana Fani Alessandri. A (re)produção do espaço urbano. São Paulo: EDUSP, 1994.

CORRÊA, Roberto Lobato. A periferia urbana. Geosul, n.2, $2^{\circ}$ sem. 1989.

COSTA, Yara Maria Marinho da. O fenômeno do granjismo e os loteamentos em Carpina. In Boletim do Instituto Joaquim Nabuco de Pesquisas Sociais. Recife: FUNDAJ, 1960.

EGLER. Claudio A. G. Subsídios à caracterização e tendências da rede urbana do Brasil configuração e dinâmica da rede urbana. Petrópolis: 2001.

GEORGE, Pierre. Geografia Urbana. São Paulo: Difel, 1983.

LAGO, Luciana Correa do. A dinâmica espacial em curso nas metrópoles brasileiras: algumas questões para discussão. In Novas periferias metropolitanas: a expansão metropolitana em Belo Horizonte: dinâmica e especificidades do eixo sul/Heloisa Soares de Moura ET AL. Belo Horizonte: C/Arte, 2006.

MIRANDA, Lívia Izabel Bezerra de. Produção do espaço e planejamento em áreas de transição rural-urbana: o caso da Região Metropolitana do Recife - PE. Tese/Lívia Miranda. - Recife: O autor, 2008.

RANDOLPH, R., GOMES, P.H.O. Mobilidade e Expansão da Metrópole para Áreas Peri-Metropolitanas - Investigando o Caso do Rio de Janeiro no Contexto Brasileiro. Rio de Janeiro: Cadernos de Metrópoles, no. 17. Rio de Janeiro, 2007.

SANCHÉZ, H. Ávila. Periurbanización y espacios rurales en la periferia de las ciudades. Estudios Agrarios. 96-123. 2009.

SILVA, A. B. Dinâmica de periurbanização na franja urbana-rural de Camaragibe: transformações espaciais e condição ocupacional dos moradores pobres num quadro de desigualdade social / Dissertação - Ailson Barbosa da Silva. Recife: O autor, 2011.

SILVA, Ailson Barbosa da. A reconfiguração de uma periferia de amenidades: à procura da natureza em Aldeia (Camaragibe-PE). Tese de Doutorado - Ailson Barbosa da Silva. - Recife: O autor, 2015.

SOUZA, Marcelo Lopes de. O desafio metropolitano: um estudo sobre a problemática sócio-espacial das metrópoles brasileiras/MLS. -Rio de Janeiro: Bertrand Brasil, 2000.

SPOSITO, Maria Encarnação Beltrão. Novos conteúdos nas periferias urbanas das cidades médias do Estado de São Paulo. Investigaciones Geográficas, Boletín del Instituto de Geografia-UNAM, núm. 54, 2004, pp. 114-139

SUDENE. Uma Política de Desenvolvimento Econômico para o Nordeste (GTDN). $3^{\text {a }}$ edição, Recife, 1978.

SVAMPA, M. Los que ganarom: La vida em los countries y Barrios privados. Buenos Ayres: Editorial Biblos, 2001. 